\title{
Pharmacology in Health Foods: Improvement of Vascular Endothelial Function by French Maritime Pine Bark Extract (Flavangenol)
}

\author{
Mamoru Ohkita $^{1}$, Yoshinobu Kiso ${ }^{2}$, and Yasuo Matsumura ${ }^{1, *}$ \\ ${ }^{1}$ Laboratory of Pathological and Molecular Pharmacology, Osaka University of Pharmaceutical Sciences, \\ 4-20-1 Nasahara, Takatsuki, Osaka 569-1094, Japan \\ ${ }^{2}$ Institute for Health Care Science, Suntory Wellness Ltd., Mishima-gun, Osaka 618-8503, Japan
}

Received December 18, 2010; Accepted February 1, 2011

\begin{abstract}
Flavangenol is the French maritime pine bark extract (PBE). It consists of a concentrate of pine bark constituents such as catechin, taxifolin, and proanthocyanidins. Recent studies have shown that PBE has a strong antioxidant effect and exerts ameliorative effects on cardiovascular, skin, cognitive, and menstrual disorders, as well as in the context of other diseases and disease processes such as diabetes and inflammation. We have also obtained evidence that Flavangenol suppresses nuclear factor-kappa B (NF- $\kappa \mathrm{B})$ activation and the subsequent various NF- $\kappa \mathrm{B}$-induced gene expressions such as those of adhesion molecules and endothelin-1 in cultured vascular endothelial cells and that the antihypertensive effect of Flavangenol on deoxycorticosterone acetatesalt hypertensive rats is attributable to both its antioxidative property-related protective effects against endothelial dysfunction and the endothelium-dependent vasorelaxant effect, which is mediated by endothelial nitric oxide synthase activation. Furthermore, Flavangenol showed a renoprotective effect on ischemia/reperfusion-induced acute kidney injury in rats. These findings suggest that Flavangenol supplementation may be a promising candidate for the improvement of endothelial dysfunction and the prophylactic treatment of vascular diseases.
\end{abstract}

Keywords: Flavangenol, hypertension, ischemia acute kidney injury, nitric oxide synthase, antioxidative effect, health food

\section{Introduction}

Flavangenol ${ }^{\circledR}$ is the French maritime pine bark extract (PBE) obtained by the hot water extraction method. The main constituents of Flavangenol are oligomeric proanthocyanidins (OPCs) that represent about $60 \%$ of all components. OPCs contained in Flavangenol are mainly composed by dimer and oligomer chains of catechin and/ or epicatechin (Fig. 1). Although Flavangenol contains a number of polyphenols such as monomer catechin and taxifolin and other proanthocyanidins, the amounts of these components are very few. On the other hand, Pycnogenol ${ }^{\circledR}$, which is obtained by using the water and ethanol extraction method, is also known as another trade

*Corresponding author. ymatsumura@gly.oups.ac.jp Published online in J-STAGE on March 24, 2011 (in advance) doi: 10.1254/jphs.10R37FM name of PBE. From long ago, PBE has been used as a historical medicinal material for the treatment of scurvy,

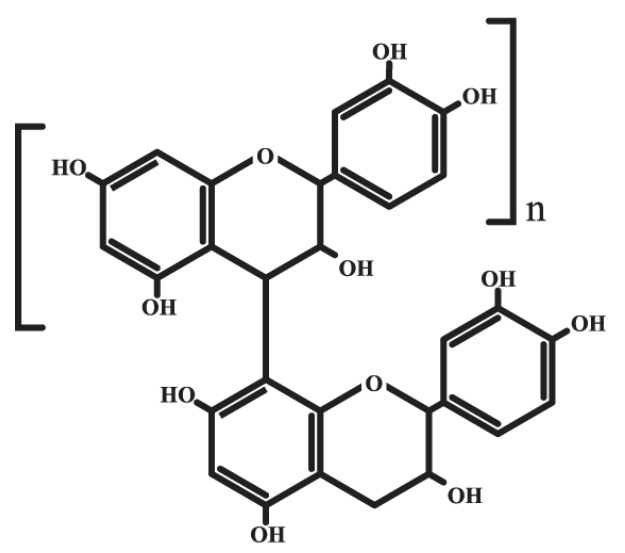

Fig. 1. Chemical structure of oligomeric proanthocyanidin. 
skin wounds, and sores (1). Recent studies have shown that the nutritional supplementation of PBE (as Pycnogenol in many cases) produces a variety of potentially protective effects against chronic age-related diseases such as atherosclerosis, hypertension, and diabetes. Although the precise mechanisms underlying the protective effects on the above diseases are not fully understood so far, dietary PBE supplementation may be useful as a prophylactic treatment in the development of cardiovascular diseases (1). This review article introduces our current findings regarding vasculoprotective and renoprotective effects of Flavangenol.

\section{Antioxidative effects of Flavangenol in hyperten- sion}

There is accumulating evidence that a number of antioxidative substances and various radical scavengers exhibit blood pressure-lowering effects in hypertensive patients $(2,3)$ and experimental animals $(4,5)$. Hypertension and related vascular alterations are closely related to an increase in reactive oxygen species (ROS) production, especially $\mathrm{O}_{2}^{-}$, in vascular tissues including endothelial cells and smooth muscle cells (6). An increased $\mathrm{O}_{2}^{-}$generation in venules and arterioles has been reported in experimental animal models such as deoxycorticosterone acetate (DOCA)-salt- and angiotensin II-induced hypertensive rats and in genetic hypertensive animals such as spontaneously hypertensive rats $(7-9)$. The role of ROS as a key factor in the development of hypertension has been confirmed by evidence indicating that the treatment with antioxidative agents to the above animals could normalize blood pressure $(10-12)$, although there are some conflicting findings indicating that antioxidant treatment of hypertensive animals had no effect on blood pressure $(13,14)$. On the other hand, it has recently been reported that many beneficial effects of PBE are closely related to its potent antioxidative and free radical scavenging function. PBE has been shown to stimulate intracellular defenses against free radicals by enhancing the production of antioxidative enzymes, in addition to excellent radical-scavenging activities (1). In vascular tissues, PBE exhibited an effective preventing action against lipid peroxidation (1). These antioxidative properties may be at least partly contributive to its protective effects against various cardiovascular diseases because increased oxidative stress is one of the major causal factors for the development of hypertension as described above $(15,16)$. In fact, our recent study has shown that the development of DOCA-salt-induced hypertension was significantly suppressed by feeding a Flavangenolcontaining diet (17). We have reported also that $\mathrm{O}_{2}^{-}$production in aortic segments tended to increase in the nor- mal diet-fed DOCA-salt rats, but Flavangenol supplementation completely suppressed this augmentation. Thus, it seems likely that the antioxidative property of Flavangenol is at least partly contributive to its antihypertensive action.

\section{Enhancement of NOS system by Flavangenol}

Several antioxidative substances have been reported to exert a preventive effect against endothelial dysfunction observed in hypertensive patients and experimental animals $(16,18,19)$. Daily feeding of PBE improves the microcirculation and platelet function in patients with coronary artery diseases. In hypertensive patients, dietary PBE supplementation decreased plasma endothelin-1 (ET-1) concentrations, while nitric oxide (NO) metabolite levels in plasma tended to be increased, suggesting the beneficial effect of PBE on endothelial function of hypertensive patients (20). A much more interesting finding is that PBE itself produced a potent vasorelaxant activity that is endothelium-dependent, as reported by Fitzpatrick et al. (21). In the in vitro experiment using isolated rat aortic rings, PBE exhibited an endotheliumdependent vasorelaxant effect, and this vasorelaxation was suppressed by the pretreatment with a non-selective NO synthase (NOS) inhibitor (21). In addition, they found also that the oligomeric (from dimers up to heptamers) proanthocyanidin fraction obtained by fractionation of PBE by Sephadex LH-20 liquid chromatography is mainly responsible for the PBE-induced vasorelaxation, although its mechanisms were not elucidated. On the other hand, our study demonstrated that Flavangenolinduced endothelium-dependent vasorelaxation was mediated by the eNOS - NO - soluble guanylate cyclase (sGC) signaling system (17). Flavangenol-induced vasorelaxation was accompanied by the increased expression of phosphorylated-eNOS $\left(\mathrm{Ser}^{1177}\right)$ protein without affecting total eNOS protein level. Furthermore, we have obtained evidence that the above increase in phosphorylated-eNOS $\left(\mathrm{Ser}^{1177}\right)$ is mediated by the PI3K/Akt pathway in cultured vascular endothelial cells. Phosphorylation mechanisms of eNOS have been extensively studied, and the most widely recognized eNOS phosphorylation site is $\operatorname{Ser}^{1177}$ (22). Phosphorylation of eNOS at $\operatorname{Ser}^{1177}$ increases eNOS activation mediated by $\mathrm{Ca}^{2+} /$ calmodulin binding (23) and can also lead to activation of eNOS at resting levels of intracellular $\mathrm{Ca}^{2+}(24)$. Some flavonoids derived from natural compounds, such as genistein, daidzein, and apigenin, have been shown to compete with $17 \beta$-estradiol for binding to the estrogen receptor, acting as phytoestrogens (25). Thus, the vasorelaxant activities of Flavangenol may result from the activation of the estrogen receptor, which is known to induce the 
enhancement of the eNOS activity $(26,27)$ and NO-mediated vasorelaxation (28). However, preincubation with the estrogen-receptor antagonist ICI 182,780 did not modify the vasorelaxant responses to Flavangenol. Thus, it is unlikely that Flavangenol acts as a phytoestrogen, at least in its vasorelaxant effects. Further evaluations are needed to determine the precise upstream mechanism by which Flavangenol stimulates eNOS-NO-sGC signaling and exhibits potent vasorelaxant activities.

\section{Renoprotective effects of Flavangenol in ischemic acute kidney injury in rats}

The post-ischemic renal injury occurs frequently in patients after major surgery, trauma, and transplantation. In general, ischemic acute kidney injury (AKI) is induced not only by the ischemia itself but also by the following reperfusion. Reperfusion of previously ischemic renal tissue initiates complex cellular events that result in injury and the eventual death of renal cells due to a combination of apoptosis and necrosis (29). The molecular mechanisms underlying the ischemia/reperfusion-induced renal injury remain unclear, but it has been reported that several causal factors (ATP depletion, phospholipase activation, neutrophil infiltration, vasoactive peptides, etc.) are contributive to the pathogenesis of this renal damage (30). Oxidative stress has also been considered as one of the factors that are definitely involved in the development of the ischemic AKI. We and others have reported that several agents possessing antioxidative activity ameliorate the ischemia/reperfusion-induced renal damage $(31-34)$. Our previous study has also shown that prior administration of Flavangenol dose-dependently overcame the ischemia/reperfusion-induced renal dysfunction in rats (35). Histological examination of the post-ischemic kidney in untreated AKI rats revealed tissue injuries, such as proteinaceous casts in tubuli, and tubular necrosis; and these lesions were significantly suppressed by pre-ischemic treatment with Flavangenol. These results indicate that Flavangenol has preventative effects on the ischemia/reperfusion-induced renal dysfunction and degeneration. Moreover, there is accumulating evidence indicating that procyanidins, which are one of the components of PBE, have a potent antioxidative activity and improve ischemia/reperfusion-induced cardiac damage $(36,37)$. Taken together with these findings, it is reasonable to consider that the beneficial effect of Flavangenol on the ischemia/reperfusion-induced renal damage is closely related to the antioxidative effects, although further studies are required to clarify how much antioxidative effects of Flavangenol are involved in the improvement of renal damage and whether procyanidins mainly play an important role in Flavangenol's action.
In many tissues, the ischemia/reperfusion induces a variety of gene expressions including those of adhesion molecules, cytokines, and vasoactive peptides $(38,39)$. It has been well known that the transcriptional factor nuclear factor-kappa $\mathrm{B}(\mathrm{NF}-\kappa \mathrm{B})$ is mainly responsible for the regulation of these gene expressions (40). We and others have demonstrated that the suppression of NF- $\kappa \mathrm{B}$ could become a novel therapeutic strategy for ischemia/ reperfusion-induced tissue damage $(41,42)$. There is accumulating evidence that PBE has an inhibitory effect on NF- $\kappa \mathrm{B}$ activation in macrophages and vascular endothelial cells $(43,44)$. We have also obtained evidence that Flavangenol suppresses NF- $\kappa$ B activation and various subsequent NF- $\kappa \mathrm{B}$-induced gene expressions such as those for adhesion molecules and ET-1 in cultured vascular endothelial cells, possibly through the inhibition of $\mathrm{I} \kappa \mathrm{B}$ phosphorylation. Thus, it is likely that inhibition of NF- $\kappa \mathrm{B}$ activation by Flavangenol treatment is related, at least, to the amelioration of ischemia/reperfusioninduced renal damage. Further studies are needed to clarify the detailed mechanisms underlying the beneficial effects of flavangenol against the ischemia/reperfusioninduced renal injury.

\section{Conclusion}

In this review, we summarized evidence of the beneficial effects of PBE. From both in vivo and in vitro evidence, it seems likely that Flavangenol supplementation may be a promising candidate for the improvement of endothelial dysfunction and the prophylactic treatment of vascular diseases. However, to determine the precise vasculoprotective and renoprotective mechanisms of Flavangenol, the most important constituent in Flavangenol with respect to exerting these actions should be identified.

\section{Acknowledgment}

This study was supported in part by a "High Technology Research Center" Project for Private Universities: matching fund subsidy from the Ministry of Education, Culture, Sports, Science, and Technology $(2007-2011)$.

\section{References}

1 Rohdewald P. A review of the French matitime pine bark extract $\left(\right.$ Pycnogenol $^{\circledR}$ ), a herbal medication with a diverse pharmacology. Int J Clin Pharmacol Ther. 2002;40:158-168.

2 Ceriello A, Giugliano D, Quatraro A, Lefebvre PJ. Anti-oxidants show an anti-hypertensive effect in diabetic and hypertensive subjects. Clin Sci (Lond). 1991;81:739-742.

3 Galley HF, Thornton J, Howdle PD, Walker BE, Webster NR. Combination oral antioxidant supplementation reduces blood pressure. Clin Sci (Lond). 1997;92:361-365. 
4 Tian N, Thrasher KD, Gundy PD, Hughson MD, Manning RD Jr. Antioxidant treatment prevents renal damage and dysfunction and reduces arterial damage and salt-sensitive hypertension. Hypertension. 2005;45:934-939.

5 Nakano D, Kwak CJ, Fujii K, Ikemura K, Satake A, Ohkita M, et al. Sesamin metabolites induce an endothelial nitric oxide-dependent vasorelaxation through their antioxidative property-independent mechanisms: possible involvement of the metabolites in the antihypertensive effect of sesamin. J Pharmacol Exp Ther. 2006;318:328-335.

6 Lassègue B, Griendling KK. Reactive oxygen species in hypertension; An update. Am J Hypertens. 2004;17:852-860.

7 Wu R, Millette E, Wu L, de Champlain J. Enhanced superoxide anion formation in vascular tissues from spontaneously hypertensive and desoxycorticosterone acetate-salt hypertensive rats. J Hypertens. 2001;19:741-748.

8 Rajagopalan S, Kurz S, Münzel T, Tarpey M, Freeman BA, Griendling KK, et al. Angiotensin II-mediated hypertension in the rat increases vascular superoxide production via membrane NADH/NADPH oxidase activation. Contribution to alterations of vasomotor tone. J Clin Invest. 1996;97:1916-1923.

9 Kerr S, Brosnan MJ, McIntyre M, Reid JL, Dominiczak AF, Hamilton CA. Superoxide anion production is increased in a model of genetic hypertension: role of the endothelium. Hypertension. 1999;33:1353-1358.

10 Nakazono K, Watanabe N, Matsuno K, Sasaki J, Sato T, Inoue M. Does superoxide underlie the pathogenesis of hypertension? Proc Natl Acad Sci U S A. 1991;88:10045-10048.

11 Laursen JB, Rajagopalan S, Galis Z, Tarpey M, Freeman BA, Harrison DG. Role of superoxide in angiotensin II-induced but not catecholamine-induced hypertension. Circulation. 1997;95: 588-593.

12 Beswick RA, Dorrance AM, Leite R, Webb RC. NADH/NADPH oxidase and enhanced superoxide production in the mineralocorticoid hypertensive rat. Hypertension. 2001;38:1107-1111.

13 Somers MJ, Mavromatis K, Galis ZS, Harrison DG. Vascular superoxide production and vasomotor function in hypertension induced by deoxycorticosterone acetate-salt. Circulation. 2000; 101:1722-1728.

14 Elmarakby AA, Loomis ED, Pollock JS, Pollock DM. NADPH oxidase inhibition attenuates oxidative stress but not hypertension produced by chronic ET-1. Hypertension. 2005;45:283287.

15 Cai H, Harrison DG. Endothelial dysfunction in cardiovascular diseases. The role of oxidant stress. Circ Res. 2000;87:840-844.

16 Endemann DH, Schiffrin EL. Endothelial dysfunction. J Am Soc Nephrol. 2004;15:1983-1992.

17 Kwak CJ, Kubo E, Fujii K, Nishimura Y, Kobuchi S, Ohkita M, et al. Antihypertensive effect of French maritime pine bark extract (Flavangenol): possible involvement of endothelial nitric oxide-dependent vasorelaxation. J Hypertens. 2009;27:92-101.

18 Plantinga Y, Ghiadoni L, Magagna A, Giannarelli C, Franzoni F, Taddei $\mathrm{S}$, et al. Supplementation with vitamins $\mathrm{C}$ and $\mathrm{E}$ improves arterial stiffness and endothelial function in essential hypertensive patients. Am J Hypertens. 2007;20:392-397.

19 Nakano D, Itoh C, Ishii F, Kawanishi H, Takaoka M, Kiso Y, et al. Effects of sesamin on aortic oxidative stress and endothelial dysfunction in deoxycorticosterone acetate-salt hypertensive rats. Biol Pharm Bull. 2003;26:1701-1705.

20 Liu X, Wei J, Tan F, Zhou S, Würthwein G, Rohdewald P.
Pycnogenol $^{\circledR}$, French maritime pine bark extract, improves endothelial function of hypertensive patients. Life Sci. 2004;74: 855-862.

21 Fitzpatrick DF, Bing B, Rohdewald P. Endothelium-dependent vascular effects of Pycnogenol. J Cardiovasc Pharmacol. 1998; 32:509-515.

22 Mount PF, Kemp BE, Power DA. Regulation of endothelial and myocardial NO synthesis by multi-site eNOS phosphorylation. J Mol Cell Cardiol. 2007;42:271-279.

23 Chen ZP, Mitchelhill KI, Michell BJ, Stapleton D, RodriguezCrespo I, Witters LA, et al. AMP-activated protein kinase phosphorylation of endothelial NO synthase. FEBS Lett. 1999;443: 285-289.

24 Montagnani M, Chen H, Barr VA, Quon MJ. Insulin-stimulated activation of eNOS is independent of $\mathrm{Ca}^{2+}$ but requires phosphorylation by Akt at Ser ${ }^{1179}$. J Biol Chem. 2001;276:30392-30398.

25 Kuiper GG, Lemmen JG, Carlsson B, Corton JC, Safe SH, van der Saag PT, et al. Interaction of estrogenic chemicals and phytoestrogens with estrogen receptor beta. Endocrinology. 1998; 139:4252-4263.

26 Chambliss KL, Yuhanna IS, Mineo C, Liu P, German Z, Sherman TS, et al. Estrogen receptor $\alpha$ and endothelial nitric oxide synthase are organized into a functional signaling module in caveolae. Circ Res. 2000;87:e44-e52.

27 Simoncini T, Abkin E, Liao JK. Molecular basis of cell membrane estrogen receptor interaction with phosphatidylinositol 3-kinase in endothelial cells. Arterioscler Thromb Vasc Biol. 2003;23:198-203.

28 Bolego C, Cignarella A, Sanvito P, Pelosi V, Pellegatta F, Puglisi $\mathrm{L}$, et al. The acute estrogenic dilation of rat aorta is mediated solely by selective estrogen receptor-alpha agonists and is abolished by estrogen deprivation. J Pharmacol Exp Ther. 2005; 313:1203-1208.

29 Lieberthal W, Levine JS. Mechanisms of apoptosis and its potential role in renal tubular epithelial cell injury. Am J Physiol. 1996;271:F477-F488.

30 Padanilam BJ. Cell death induced by acute renal injury: a perspective on the contributions of apoptosis and necrosis. Am J Physiol Renal Physiol. 2003;284:F608-F627.

31 Fujii T, Takaoka M, Muraoka T, Kurata H, Tsuruoka N, Ono H, et al. Preventive effect of L-carnosine on ischemia/reperfusioninduced acute renal failure in rats. Eur J Pharmacol. 2003;474: 261-267.

32 Takaoka M, Ohkita M, Kobayashi T, Yuba M, Matusmura Y. Protective effect of alpha-lipoic acid against ischaemic acute renal failure in rats. Clin Exp Pharmacol Physiol. 2002;29: 189-194.

33 Doi K, Suzuki Y, Nakao A, Fujita T, Noiri E. Radical scavenger edaravone developed for clinical use ameliorates ischemia/reperfusion injury in rat kidney. Kidney Int. 2004;65:1714-1723.

34 Kasuno K, Nakamura H, Ono T, Muso E, Yodoi J. Protective roles of thioredoxin, a redox-regulating protein, in renal ischemia/reperfusion injury. Kidney Int. 2003;64:1273-1282.

35 Ohkita M, Nakajima A, Ueda K, Takaoka M, Kiso Y, Matsumura Y. Preventive effect of Flavangenol on ischemia/reperfusioninduced acute renal failure in rats. Biol Pharm Bull. 2005;28: 1655-1657.

36 Maffei Facino R, Carini M, Aldini G, Berti F, Rossoni G, Bombardelli E, et al. Procyanidines from Vitis vinifera seeds protect rabbit heart from ischemia/reperfusion injury: antioxidant 
intervention and/or iron and copper sequestering ability. Planta Med. 1996;62:495-502.

37 Maffei Facino R, Carini M, Aldini G, Berti F, Rossoni G, Bombardelli E, et al. Diet enriched with procyanidins enhances antioxidant activity and reduces myocardial post-ischaemic damage in rats. Life Sci. 1999;64:627-642.

38 Lipton P. Ischemic cell death in brain neurons. Physiol Rev. 1999;79:1431-1568.

39 Devarajan P, Mishra J, Supavekin S, Patterson LT, Steven Potter $\mathrm{S}$. Gene expression in early ischemic renal injury: clues towards pathogenesis, biomarker discovery, and novel therapeutics. Mol Genet Metab. 2003;80:365-376.

40 Richmond A. NF-kappa B, chemokine gene transcription and tumour growth. Nat Rev Immunol. 2002;2:664-674.

41 Takaoka M, Matsumura Y. Pathophysiological role of endothelin in ischemic acute renal failure. Recent Res Devel Life Sci. 2003;
1:203-220.

42 Azuma H, Tomita N, Kaneda Y, Koike H, Ogihara T, Katsuoka Y, et al. Transfection of NFkappaB-decoy oligodeoxynucleotides using efficient ultrasound-mediated gene transfer into donor kidneys prolonged survival of rat renal allografts. Gene Ther. 2003; 10:415-425.

43 Peng Q, Wei Z, Lau BH. Pycnogenol inhibits tumor necrosis factor-alpha-induced nuclear factor kappa B activation and adhesion molecule expression in human vascular endothelial cells. Cell Mol Life Sci. 2000;57:834-841.

44 Cho KJ, Yun CH, Yoon DY, Cho YS, Rimbach G, Packer L, et al. Effect of bioflavonoids extracted from the bark of Pinus maritima on proinflammatory cytokine interleukin-1 production in lipopolysaccharide-stimulated RAW 264.7. Toxicol Appl Pharmacol. 2000;168:64-71. 